\title{
A PEDAGOGIA TECNICISTA E A ORGANIZAÇÃO DO SISTEMA DE ENSINO BRASILEIRO
}

\author{
Andréa Villela Mafra da Silva ${ }^{1}$
}

\section{RESUMO}

Este texto apresenta as ideias básicas que constituem a pedagogia tecnicista com o objetivo de compreender o contexto em que essa tendência foi se delineando na organização do sistema de ensino brasileiro. Para tal, o texto mostra um breve retrospecto histórico do desenvolvimento do sistema capitalista com o objetivo de identificar os antecedentes históricos e as bases de sustentação teórica do modelo tecnicista de educação. Metodologicamente, foi utilizada a pesquisa bibliográfica. O referencial teórico tem aporte em autores como Libâneo (1982), Saviani (2007, 2008, 2010), dentre outros, que me auxiliaram na problematização do tema. Concluo que no modelo tecnicista de educação a exigência da produtividade, por intermédio da racionalização do sistema de ensino, propõe objetivos de ensino fragmentados. Há uma ênfase nos meios que passam a determinar os objetivos. Isto posto, há uma inversão no processo pedagógico, de modo que as técnicas determinam os fins. Em outros termos, ocorre uma mudança qualitativa na organização do trabalho pedagógico da escola, que passa a ter como base um ensino que busca resultado uniforme, com ênfase em métodos e técnicas de ensino e na valorização da utilização de manuais, livros didáticos, módulos de ensino e recursos audiovisuais. Este texto é parte da minha pesquisa de doutorado ainda em andamento.

Palavras chave: Pedagogia Tecnicista; Objetivação do trabalho pedagógico; Racionalização do Ensino.

\begin{abstract}
This text presents the basic ideas that constitute the technical pedagogy with the objective of understanding the context in which this tendency was being delineated in the organization of the Brazilian education system. For this, the text shows a brief historical retrospective of the development of the capitalist system with the objective of identifying the historical antecedents and bases of theoretical support of the pedagogic technicist. Methodologically, the bibliographic research was used. The theoretical framework has contributed to the study of librarianship in Libâneo (1982), Saviani (2007, 2008), among others, who helped me in the problematization of the theme. In this way, there is a reversal in the pedagogical process, so that the techniques determine the ends. In other words, there is a qualitative change in the Organization of the pedagogical work of the school, which is based on a teaching that seeks a uniform result, with emphasis on teaching methods and techniques and on the use of manuals, textbooks, teaching modules and audiovisual resources. Of my doctoral research, still in progress.
\end{abstract}

Keywords: Technician Pedagogy; Objectivation of pedagogical work; Rationalization of Teaching. 


\section{Introdução}

O pensamento educacional brasileiro tem sido marcado pela tendência liberal de educação, quer nas formas conservadora ou renovada, que são materializadas nas práticas escolares. Nos termos de Libâneo (1982), a doutrina liberal apareceu como justificativa do sistema capitalista que, ao defender a predominância da liberdade e dos interesses individuais na sociedade, estabeleceu uma forma de organização social baseada na propriedade privada dos meios de produção. Nessa direção, a pedagogia liberal, portanto, é uma manifestação própria desse tipo de sociedade se sustentando, principalmente, na ideia de que a escola tem como função preparar os sujeitos para o desempenho de papéis sociais, tendo em conta as aptidões individuais. Mas, para que isso ocorra, é necessário aprender a se adaptar aos valores e às normas vigentes da sociedade.

No campo educacional, a tendência liberal tecnicista atua no aperfeiçoamento do sistema capitalista, alinhando-se com o sistema produtivo; para tanto, seu interesse é produzir indivíduos competentes para o mercado de trabalho. Digno de nota, o conceito de competência como algo adequado ao desempenho proposto ou qualificado para "ser admitido a" ou "como ser capaz de" revelam o significado do termo associado ao contexto da crise estrutural do sistema capitalista, em que o trabalhador tinha que adequar-se às exigências da produção. Nessas circunstâncias, a lógica do modelo de competências aplicado à Educação parte de uma concepção centrada nos objetivos do ensino, expressados em termos comportamentais, e na utilização de técnicas específicas nas práticas pedagógicas. $\mathrm{O}$ discurso baseado no conceito de competência e qualificação supõe que todos os indivíduos possam adquirir um repertório comum de habilidades, por intermédio de treinamento institucionalizado, desconsiderando os aspectos individuais inerentes a cada trabalhador (FAIRCLOUGH, 2001).

Nessa mesma perspectiva, o discurso da pedagogia tecnicista se coaduna com a lógica do modelo de competências ao ter como base uma educação que privilegia a lógica da instrução e a transmissão da informação. Mais especificamente, o reducionismo tecnicista - em que a formação de professores parte da dimensão acadêmica para a dimensão experimental/instrumental/pragmática e coloca a ênfase nas competências e habilidades dos professores e alunos busca, prioritariamente, o alcance das metas e resultados préestabelecidos para assim garantir a eficiência e a produtividade na educação. Isto posto, o paradigma tecnicista centrado nos conceitos de competências e habilidades se faz presente na organização e funcionamento das escolas, através do método de gerenciamento produtivo-industrial, que por sua vez, tem como base a busca pela qualidade total (SAVIANI, 2007).

Desse modo, examinar as ideias básicas que constituem a pedagogia tecnicista é uma tarefa imprescindível para compreender o contexto em que essa tendência foi se delineando na organização do sistema de ensino brasileiro, à luz de referenciais que explicam o sistema do capital.

Por esse motivo, farei um breve retrospecto histórico do desenvolvimento do sistema capitalista, destacando que as análises empreendidas não serão aprofundadas já que pretendem apenas localizar o contexto histórico do modelo tecnicista de educação. Teço algumas considerações sobre o Taylorismo/Fordismo/Toyotismo que, como modelos de racionalização típicos do sistema de produção capitalista, serviram de orientação para o tecnicismo aplicado à educação. Apresento as bases de sustentação teórica do tecnicismo sob a influência da filosofia positivista e da pedagogia behaviorista. Por fim, abordo os acordos MEC-USAID que, por intermédio de cooperação técnica e financeira, 
implementaram no território brasileiro propostas de reformas no ensino, de acordo com padrões estadunidenses.

\section{Antecedentes históricos}

\section{Taylorismo e Fordismo}

No século XVIII, a partir do surgimento das fábricas tem-se os trabalhadores submetidos a uma mudança radical com os hábitos adquiridos nas manufaturas. Os trabalhadores - que antes do surgimento das fábricas, realizavam trabalhos predominantemente artesanais - no sistema fabril, as relações de trabalho são caracterizadas pela execução de tarefas cada vez mais mecanizadas e fragmentadas, com o objetivo de buscar economia de tempo e o máximo de produtividade. Se no artesanato o trabalho era subjetivo, ou seja, os instrumentos de trabalho estavam disponíveis em função do trabalhador e este dispunha deles conforme suas necessidades, na produção fabril essa relação é invertida (SAVIANI, 2007).

Nestas condições, expropriou-se do trabalhador o conhecimento típico das massas produtivas artesanais para substituí-lo pelo conhecimento da ciência e da tecnologia. Em outras palavras, as implicações da ciência e da tecnologia no contexto do trabalho, encaminham a um inexorável processo de expropriação do conhecimento do artesão e a novas formas de exploração, concentrando nas mãos do empresariado os meios de produção inacessíveis à sociedade em geral. De fato, a implantação da economia de mercado faz surgir as duas classes sociais antagônicas e fundamentais ao capitalismo - os proprietários e os não-proprietários, ou os que exploram e os que são explorados nas relações de trabalho.

Em fins do século XIX e início do século XX, a organização do processo produtivo com a criação da Teoria Geral de Administração, cujo representante é Frederick Winslow Taylor (1856-1915) ${ }^{2}$ teve como objetivo o aumento da eficiência, através do estabelecimento de regras detalhadas de atuação no trabalho e do estabelecimento de um tempo padrão para a sua execução, que constitui a chamada Organização Racional do Trabalho (CHIAVENATO, 2003).

A principal característica do método taylorista de trabalho é o controle de todas as fases de produção, estabelecendo as etapas de execução do trabalho, sob a égide da burocratização. O Taylorismo se apoia no conceito da eficiência como um dos principais critérios de avaliação dos processos produtivos. Faz uso da competição entre os trabalhadores, nos setores de execução das etapas do trabalho, utilizando instrumentos de gratificações e promoções. No entanto, contraditoriamente, a despeito da competitividade, submete os trabalhadores a uma homogeneização para manter o controle, a eficiência e a eficácia nos processos de produtivos.

Foi no âmbito do método taylorista de controle sobre o trabalho que se propôs: (a) a separação entre o planejamento do trabalho e a sua execução, de forma a possibilitar que o planejador controle cada fase do processo do trabalhador que executa a tarefa; (b) a gerência que controla todas as etapas de execução, impondo ao trabalhador a maneira como a tarefa deverá ser realizada; (c) o treinamento para executar as tarefas.

Isto é, a divisão manufatureira que separa a decisão da execução - fragmentando a organização do trabalho em inúmeras partes - passou a exigir baixos níveis de qualificação dos trabalhadores. Do ponto de vista de aplicação prática, o trabalhador passa a não ter poder de decisão sobre o resultado final do seu trabalho e também (sobre este) não detém nenhum controle sobre a finalidade ou o objetivo do que produz. Ao executar o seu trabalho, repete e reproduz atividades mecânicas à revelia de suas necessidades e intenções. 
Ainda no século XX, outro tipo de método de racionalização do trabalho industrial foi concebido por Henry Ford (1863-1947) com a introdução das linhas de montagem na indústria automobilística. À Henry Ford é atribuído o fordismo, que, por definição, se refere a produção em grande quantidade de automóveis a baixo custo, utilizando as linhas de montagens que possibilitavam fabricar um carro a cada 98 minutos ${ }^{3}$. Henry Ford fundou a Ford Motor Company, introduzindo a montagem em série, para produzir automóveis em menos tempo e com menor custo, utilizando a exploração intensa do trabalhador que, com suas atividades repetitivas e massificadas, era considerado o elemento fundamental para o aumento do lucro das fábricas. Desse modo, o modelo fordista caracteriza-se pela produção em massa e pelo controle do tempo de trabalho.

A linha de montagem e as técnicas de fabricação em série de Henry Ford definiu padrões do processo industrial, na primeira metade do século XX. Foi através destas técnicas de fabricação que se introduziu o uso de robôs industriais e a produção informatizada. Inspirado no método idealizado por Frederick Winslow Taylor, a inovação proposta pelo fordismo foi a introdução de linhas de montagem em que o trabalhador era responsável apenas por uma atividade. Nas palavras de Antunes (2009, p. 38-39), os dois modelos de produção - taylorismo/ fordismo - baseavam-se na produção em massa de mercadorias, a partir de uma produção homogeneizada e verticalizada que se estruturou na perda da destreza do trabalhador ${ }^{4}$.

A lógica do modelo de produção taylorista e fordista introduziu nas relações de trabalho elementos feitichizadores e alienantes de controle social para racionalizar ao máximo as tarefas realizadas pelos trabalhadores. Reduzir o tempo e aumentar o ritmo de trabalho era uma das formas de intensificar a exploração dos trabalhadores. A precarização do trabalho foi então instituída a partir da "mescla da produção em série fordista com o cronômetro taylorista", além do estabelecimento da separação entre a elaboração e a execução do trabalho (ANTUNES, 2009, p. 39). Tratava-se de suprimir a dimensão do trabalho intelectual do operário, com a desqualificação de suas atividades, através de ações repetitivas, e concentrar nos setores de gerência o controle da produção.

O processo de massificação ocorrido durante o período taylorista/fordista entrou em crise evidenciando: (a) a queda da taxa de lucro; (b) aumento do preço da força de trabalho; (c) intensificação das lutas sociais dos anos de 1960; (d) esgotamento do padrão de acumulação de produção taylorista/fordista que se mostrava incapaz de responder à retração do consumo e do desemprego estrutural que então se iniciava; (e) incremento acentuado das privatizações; dentre outros aspectos (ANTUNES, 2009, p. 31-32).

Dada a complexidade dos elementos fundamentais para o detalhamento da crise no mundo do trabalho, o destaque está nos sinais de esgotamento do movimento operário que afetou fortemente as relações de produção. No final dos anos 1960, ocorreu a revolta dos trabalhadores contra os métodos tayloristalfordista de produção, desde manifestações de descontentamento individualizadas, até formas de ações de resistências coletivas, como as greves. Nestas circunstâncias, o estancamento econômico e as lutas de classes tiveram papel fundamental na crise dos finais dos anos 1960 e início dos anos 1970; no entanto, não foram suficientes "para se converter num projeto societal hegemônico contrário ao capital" (ANTUNES, 2009, p.46). Para Antunes ${ }^{5}$, a contestação do poder do capital não se estendeu aos movimentos sociais e não foram capazes de se contrapor aos sindicatos e aos partidos políticos.

Por fim, Taylorismo/Fordismo como modelos de racionalização do sistema de produção capitalista serviram como orientação para o tecnicismo aplicado à educação. Do paradigma taylorista decorre a fragmentação curricular, no trabalho pedagógico, ao dividir o conhecimento em áreas e disciplinas com suas cargas horárias por séries e turmas de forma 
aleatória, "supondo que a unidade rompida se recupere como consequência 'natural' das práticas curriculares, ficando por conta do aluno a reconstituição das relações que se estabelecem entre os diversos conteúdos disciplinares" (KUENZER, 2005, p. 81).

\section{Toyotismo: $O$ discurso da qualidade total}

O processo de reestruturação produtiva, a partir da crise do final dos anos de 1960, passou a exigir do trabalhador um conhecimento mais alinhado ao processo produtivo e às determinações das políticas neoliberais. A reorganização capitalista no mundo do trabalho, a partir do avanço tecnológico, remodelou os sistemas de administração das empresas, implantando o Toyotismo com a busca pela qualidade total e outras técnicas de gestão. A resposta do capital à crise no mundo do trabalho fabril foi o enorme salto tecnológico que criou novas formas de organização da produção, em que a divisão em trabalho manual e intelectual, historicamente concebidos, não serviam mais ao modelo toyotista (ANTUNES, 2009).

O sistema Toyota de produção intensificou a racionalização da produção, a partir da organização e do controle do trabalho. O Toyotismo se diferenciava do modelo taylorista/fordista, por buscar inovações no desenvolvimento de técnicas e métodos no processo produtivo que não gerassem custos desnecessários. $\mathrm{O}$ controle sobre os processos produtivos tinha como objetivo reduzir também os tempos de produção.

Conceitos como competência, qualidade, motivação são inerentes ao sistema Toyota de produção e que foram absorvidos pela Educação, por exemplo, nas bases ideológicas que sustentam os pilares da Educação para o século XXI. O conceito de aprender a fazer como um dos pilares do Relatório para a Unesco da Comissão Internacional sobre Educação para o século XXI, do qual o educador francês, Jacques Delors, é relator, tem relação direta com o paradigma tecnicista presente nas técnicas de ensino industrial difundidas no Brasil com a criação do Serviço Nacional de Aprendizagem Industrial (SENAI). De modo específico, Delors (1996) indica que há uma relação entre o pilar aprender a fazer com o sistema Toyota de produção ao afirmar que:

O aumento de exigências em matéria de qualificação, em todos os níveis, tem várias origens. No que diz respeito ao pessoal de execução, a justaposição de trabalhos prescritos e parcelados deu lugar à organização em 'coletivos de trabalho' ou 'grupos de projeto', a exemplo do que se faz nas empresas japonesas: uma espécie de taylorismo ao contrário (DELORS, 1996, p. 94, grifo meu).

O discurso do Relatório de Jacques Delors (1996) pretendeu constituir o ordenamento da Educação, através de suas recomendações, com a noção de competência associada a qualificação do trabalhador. Na perspectiva de Delors (1996), "a exigência de uma qualificação ainda muito ligada", a seu ver, "a uma espécie de coquetel individual, combinando a qualificação, em sentido estrito, adquirida pela formação técnica e profissional" (p.04). Não se pode perder de vista que a noção de competência requer uma permanente adaptação do trabalhador às atividades de trabalho e às demandas de mercado e de produto. A noção de competência, impulsionada pelo Sistema Toyota de Produção, a partir do discurso pautado na necessidade de qualificação e profissionalização dos trabalhadores, exigiu um trabalhador polivalente, com aptidões técnicas para o cumprimento de suas atividades profissionais. 


\section{As Bases De Sustentação Teórica Da Pedagogia Tecnicista}

\section{Do Empirismo ao Positivismo}

O empirismo e o positivismo marcam fortemente o início da constituição do método das ciências humanas, no final do século XIX e começo do século XX (MANACORDA, 1989). O empirismo (palavra de origem grega empeiria, experiência sensorial) se baseia na crença de que a formação de ideias e o conhecimento se originam unicamente pela experiência prática. Ou seja, a origem do conhecimento está na experiência sensível, proveniente das percepções sensoriais.

Entre os principais representantes do empirismo que surge na Inglaterra, a partir do século VVII, destacam-se Francis Bacon (1561- 1626), Thomas Hobbes (1588 - 1679), John Locke (1632 - 1704), George Berkeley (1685 - 1753) e David Hume (1711 - 1776),

Nascido na Inglaterra, John Locke é considerado o protagonista do empirismo. Em sua obra "Ensaio acerca do entendimento humano", nega que o homem possua ideias inatas. Locke defendeu a ideia de que a mente, no instante do nascimento, é uma tábula rasa. Sua tese tem como fundamento a noção de que o conhecimento é adquirido ao longo da vida com o exercício da experiência sensorial e da reflexão. Entretanto, Locke admitiu que nem todo conhecimento estava limitado a experiência sensorial, como o conhecimento matemático válido que, em termos lógicos, necessariamente não precisa ter como base a experiência sensorial.

O positivismo amplia a tese empirista, na medida em que considera como válidos os conhecimentos que podem ser observados e também testados cientificamente. O positivismo - como designação da doutrina criada por Augusto Comte (1789-1857) - manifesta-se no entusiasmo pelo progresso capitalista e pelo desenvolvimento técnico industrial. Como corrente ideológica, define uma diretriz de culto da ciência e da sacralização do método cientifico. O objetivo do método de investigação positivista é a pesquisa das leis gerais que regem os fenômenos naturais. As transformações alavancadas pelas ciências visam o progresso, que por sua vez, está subordinado à ordem; daí o lema positivista representado na proposição Ordem e Progresso inscrito na Bandeira do Brasil.

$\mathrm{Na}$ Educação, a influência do positivismo se traduziu nos pressupostos da Psicologia e da Sociologia como ciências auxiliares. No positivismo defendia-se uma escola laica, através da substituição do currículo acadêmico por um currículo enciclopédico, com a inclusão das disciplinas científicas, como Matemática, Astronomia, Física, Química, Biologia e Sociologia, buscando romper com a tradição pedagógica católica humanista. Tratava-se de suprimir dos currículos aqueles elementos que ensejavam a formação cristã, incorporando uma doutrina que difundisse os valores do nacionalismo e da cidadania, dentro de um clima de entusiasmo patriótico (SILVA, 2004).

É, pois, o empirismo e o positivismo que vão constituir o método das ciências humanas, particularmente, no campo da Pedagogia, o cientificismo, que preconiza como conhecimento válido o que tem como base a observação e a experimentação. É também do cientificismo que se origina a pedagogia tecnicista.

\section{A Teoria Behaviorista da aprendizagem: o processo educativo objetivo e operacional}

Outra corrente presente nas bases de sustentação teórica da pedagogia tecnicista é o behaviorismo (behavior, conduta) ou psicologia comportamentalista. A teoria behaviorista da aprendizagem surgiu na Europa e foi desenvolvida nos Estados Unidos da América do 
Norte, de onde se expandiu para outros países. Os principais behavioristas foram: (a) John Broadus Watson (1878-1958) fundador da teoria behaviorista;(b) Ivan Petrovich Pavlov (1849 - 1936), fisiologista russo conhecido principalmente pelo seu trabalho com condicionamento clássico; (c) Burrhus Frederic Skinner (1904 - 1990); (d) Edward Lee Thorndike (1874 - 1949).

O behaviorismo que preconiza a organização das situações, através da seleção e da associação de estímulos, inicialmente, inspirou-se nas experiências com reflexo condicionado de Pavlov, no entanto, desenvolveu-se com os trabalhos em psicologia experimental de Burrhus Frederic Skinner (1904 -1990).

No campo da teoria behaviorista, o princípio de condicionamento se baseia no associacionismo que se refere à associação de dois estímulos, sendo que um destes funciona como reforço de uma resposta. Burrhus Frederic Skinner aperfeiçoou os estudos de condicionamento clássico utilizando experiências, com ratos e pombos, com o uso da "caixa de Skinner" - dentro da qual era colocado um animal faminto. A experiência consistia na situação em que o animal casualmente esbarrava em uma alavanca e o alimento caía dentro da caixa. Depois de esbarrar diversas vezes na alavanca o animal passava, então, a acionar a alavanca sempre que desejava obter alimento.

Ao reportar essa experiência ao princípio de aprendizagem humana, Skinner inventa a instrução programada através da máquina de ensinar. O método de ensino skinneriano consiste nos procedimentos e técnicas necessários ao controle do processo ensino e aprendizagem, através do estabelecimento de: (i) objetivos instrucionais; (ii) ordenação sequencial da instrução e, (iii) reforço gradual das respostas correspondentes aos objetivos. Skinner assegurou que as sequências de aquisições no ensino garantiriam o mínimo de erros e o máximo de recompensas no processo pedagógico.

No campo da Educação, o behaviorismo dá ênfase ao reforço como determinante da aprendizagem e compreende as aquisições dos alunos, a partir dos acontecimentos externos, como por exemplo, as características motivadoras expressas no ambiente da escola e na família.

\section{A Teoria de Capital Humano}

A Teoria de Capital Humano, cunhada por Theodore Schultz, em 1961, tem como base a perspectiva da economia americana que buscava uma correlação entre o investimento na formação do trabalhador e a distribuição de renda pessoal. Em 1965, Theodore Schultz publica o livro The economic value of education que trata, dentre outros temas, da relação entre a esfera privada e a formação profissional, a realização da pesquisa científica e o desenvolvimento de novas tecnologias, na sociedade americana.

O conceito de capital humano, tal como era desenvolvido por Schultz (1961), encerrava uma compreensão de trabalho apenas como uma capacidade de realizar uma tarefa manual que exigisse escasso conhecimento e especialização. $\mathrm{Na}$ linha central do desenvolvimento do conceito o investimento em capital humano se refere ao investimento em escolaridade, treinamento e saúde do trabalhador.

No campo da Educação, a teoria de capital humano gerou a concepção tecnicista sobre o ensino e sobre a organização da educação. Na concepção tecnicista, propagou-se a ideia de que a educação é o pressuposto do desenvolvimento econômico, chancelando a noção de que os investimentos em educação devem ser determinados pelos critérios do investimento capitalista. Nessa perspectiva, a teoria de capital humano deslocou para o âmbito individual os problemas da inserção social, do emprego e do desempenho profissional e fez da Educação um valor econômico. 


\section{A Concepção Pedagógica Tecnicista no Brasil}

No contexto das políticas educacionais brasileiras, a Teoria de Capital Humano está atrelada a criação do Instituto de Pesquisas e Estudos Sociais (IPES), em 29 de novembro de 1961, com a participação de um grupo de empresários dos Estados do Rio de Janeiro e São Paulo, articulados com empresários de multinacionais e da Escola Superior de Guerra (ESG). Fundado no processo de acirramento da luta política e da desestabilização do governo João Goulart (1961 a 1964) ${ }^{6}$, o IPES buscava retirar dos políticos o controle sobre o Estado. Na Educação, o IPES influenciou na definição das políticas com o objetivo de transformar a universidade em um espaço alinhado aos interesses da indústria.

Dentre as atividades desenvolvidas pelo IPES, há destaque para dois grandes eventos no campo da educação que foram o Simpósio sobre a Reforma da Educação e o fórum $A$ educação que nos convém.

Sem a intenção de tratar o fórum A educação que nos convém como ícone de maior importância, também não é possível desconsiderar a sua ampla repercussão, bem como os seus fundamentos que passaram a constituir a orientação pedagógica assumida no contexto da ditadura militar no Brasil (DREIFUSS, 1981; SAVIANI, 2007, 2008). Para Saviani (2007), o sentido geral desse fórum é traduzido "pela ênfase nos elementos dispostos pela Teoria do Capital Humano e "na educação como formação de recursos humanos para o desenvolvimento econômico dentro dos parâmetros da ordem capitalista" (p.342).

No campo educacional, a instituição das reformas de ensino e as alterações nas bases organizacionais para ajustar a educação ao modelo econômico do capitalismo ficaram evidenciadas nos princípios da Lei $n^{\circ} 5.540 / 68$ e da Lei $n^{\circ}$ 5.692/71. A Reforma Universitária através da Lei 5.540, de 28 de novembro de 1968, complementada pelo Decreto-Lei $\mathrm{n}^{\circ}$ 464, de 11 de fevereiro de 1969, foi implantada como resposta ao apelo da sociedade que clamava por mais vagas no ensino superior e pela demanda dos professores "que reivindicavam a abolição da cátedra, a autonomia universitária e mais verbas e mais vagas para desenvolver pesquisas e ampliar o raio de ação da universidade" além da demanda dos grupos ligados ao regime instalado com o golpe militar "que buscavam vincular mais fortemente o ensino superior aos mecanismos de mercado e ao projeto político de modernização em consonância com os requerimentos do capitalismo internacional" (SAVIANI, 2010, p. 9).

Já a Lei no 5.692/1971 introduziu nas escolas brasileiras um currículo por áreas de estudo (não reconhecendo as disciplinas científicas) e com ênfase no desenvolvimento de habilidades, atitudes e conhecimentos necessários à integração no processo produtivo. A reforma educacional de 1971 introduz alterações, no nível secundário, ao determinar que o ensino profissional seja obrigatório para todos os jovens brasileiros. As principais mudanças foram a extensão da obrigatoriedade escolar para oito anos, com a fusão dos antigos cursos primários e ginásio e a extinção do exame de admissão; a introdução do ensino profissionalizante através dos ginásios orientados para o trabalho e a implantação da profissionalização compulsória no ensino de $2^{\circ}$ grau. Em outras palavras, a Lei $n^{\circ}$ 5.692/71 preconiza a sondagem de aptidões e a iniciação para o trabalho com uma atenção maior para as questões de profissionalização e, em decorrência com a inserção no mercado de trabalho. Nesse contexto, a pedagogia tecnicista introduziu nas escolas brasileiras um currículo por áreas de estudo, com ênfase no desenvolvimento de habilidades, atitudes e conhecimentos necessários à integração no processo produtivo. 


\section{Os convênios entre o Ministério da Educação e Cultura e a Agência Norte Americana para o Desenvolvimento Internacional: os acordos MEC-USAID}

No Brasil, uma série de acordos entre o Ministério da Educação (MEC) e a United States Agency for International Development (USAID) promoveram convênios de assistência técnica e cooperação financeira:

(a) convênios entre o Ministério da Educação e Cultura e a Agência Norte Americana para o Desenvolvimento Internacional (acordos MEC-USAID), que faziam parte do programa Aliança para o Progresso;

(b) Simpósio Interamericano de Administração Educacional realizado em Brasília, em outubro de 1968, promovido pela Organização dos Estados Americanos (OEA), pelo Instituto Nacional de Estudos e Pesquisas Educacionais Anísio Teixeira (INEP), e pela Associação Nacional de Profissionais de Administração Educacional (ANPAE). Nesse simpósio, foi apresentado o primeiro texto de que se tem conhecimento sobre a Teoria Geral dos Sistemas à Educação, que serviu de base para inúmeros trabalhos posteriores no Brasil;

(c) elaboração do Advanced System for Comunications and Education in National Development (ASCEND), em 1966. Através de uma iniciativa conjunta do Ministério da Educação, do Centro Nacional de Pesquisas e Desenvolvimento Tecnológico (CNPq) e do Instituto Nacional de Pesquisas Espaciais (INPE), o relatório indicava a eficácia de um protótipo de sistema de utilização do audiovisual - vista como uma solução, no contexto dos anos 1970, quando o número de analfabetos no Brasil era considerado um entrave à modernização do país, principalmente nas regiões Norte e Nordeste. O projeto, conhecido como SACI, utilizava o formato de telenovela, fornecendo aulas pré-gravadas, transmitida via satélite, com suporte em material impresso, para alunos das séries iniciais e para professores leigos, do então ensino primário no Estado do Rio Grande do Norte - onde foi implantado um projeto piloto. Em 1976, registrou-se um total de 1.241 programas de rádio e TV, realizados com recepção em 510 escolas de 71 municípios. O projeto foi interrompido em 1978, sob o argumento dos altos custos de manutenção dos satélites e das diferenças culturais entre o perfil dos programas, produzidos no interior do Estado de São Paulo;

(d) as intervenções da United Nation Educational, Scientific and Cultural Organization (UNESCO) na educação da América Latina (KUENZER, MACHADO, 1996).

As premissas do acordo MEC-USAID, partem da incorporação das ideias pedagógicas tecnicistas na organização do sistema de ensino, especialmente, nas questões ligadas ao conteúdo, aos atos de currículo, às estratégias de ensino, aos recursos e à avaliação que desconsiderou as dimensões política, social e ideológica, que lhes são inerentes. A padronização e a homogeneidade do processo de ensino e aprendizagem foram instituídas na forma de planejamentos previamente formulados. Isto é, da mesma forma que a concepção do trabalho fabril, a pedagogia tecnicista se sustenta nos pressupostos da objetividade e racionalidade buscando minimizar as interferências subjetivas, através da mecanização do processo educativo. Sob essa perspectiva, ao se analisar o ato do conhecimento no paradigma tecnicista, o foco está no objeto a ser conhecido e não no trabalho intelectual do sujeito. Outro aspecto é o reducionismo tecnicista que desconsidera a complexidade do processo pedagógico quando remete as relações na escola, meramente à aplicação de técnicas.

Nos termos de Saviani (2007, p. 381), a pedagogia tecnicista, ao transpor para a escola "a forma de funcionamento do sistema fabril, perdeu a especificidade da educação, ignorando que a articulação entre escola e o processo produtivo se dá de modo indireto e por meio de complexas mediações".

No contexto MEC-USAID foram assinados vários contratos de cooperação, dentre estes, o Programa de Assistência Brasileiro-Americana ao Ensino Elementar (PABAEE), 
firmado em junho de 1956, com o objetivo de melhorar o ensino elementar brasileiro. Esse acordo surgiu da análise da situação do ensino primário, nos anos 1950, que apresentava altos índices de evasão e repetência, elevado número de professores leigos e a utilização de material didático inadequado. Outro fator destacado pelo PABAEE foi que o fracasso da escola estava relacionado à baixa qualificação do corpo docente e que seria necessário o investimento na formação do professor primário.

A cooperação técnica proposta pelo PABAEE e o encaminhamento das ações pedagógicas nas escolas brasileiras desencadeou reações contrárias entre os professores e na comunidade escolar, em geral. Professores, pais e alunos, ao se posicionarem contra as propostas de reformas, contribuíram para a não concretização das mudanças anunciadas pelo PABAEE.

Paiva e Paixão (2002) publicaram o livro intitulado PABAEE (1956-1964) que apresenta como temática central a reconstituição histórica da implantação e o desenvolvimento deste programa no Brasil. As autoras ${ }^{7}$ destacam que, no campo das políticas de formação dos professores, o PABAEE promoveu cursos de aperfeiçoamento e de especialização, com o apoio do Instituto Nacional de Estudos e Pesquisas Educacionais Anísio Teixeira (INEP) e com a participação de diversos docentes de instituições americanas de ensino.

No Brasil, entre 1959 e 1964, foram realizados cursos supervisionados por técnicos americanos para 864 bolsistas oriundos de todas as unidades da federação brasileira, que à época, abrangia 21 Estados e o Distrito Federal (PAIVA, PAIXÃO, 2002). As autoras chamam a atenção para a ênfase que o PABAEE atribuía a utilização das tecnologias na escola, com a projeção de filmes didáticos confeccionados nos Estados Unidos da América do Norte. Segundo as autoras, os objetivos e as ações apresentadas pelo PABAEE estão relacionados à perspectiva tecnicista que ao assegurar, por exemplo, a criação de alternativas técnico-metodológicas nas práticas pedagógicas, valorizam a utilização intensiva de recursos audiovisuais, partindo da ideia de que estes são prioritários na promoção da aprendizagem na escola.

A influência do PABAEE, no campo do currículo no Brasil, resultou na criação de departamentos nas faculdades e nas universidades do país para tratar, especificamente, de currículo e supervisão, e especialmente, para se dedicar à promoção de cursos para os professores sobre questões curriculares.

\section{Considerações Finais}

O presente artigo teve o objetivo de apresentar as ideias básicas que constituem a pedagogia tecnicista para compreender o contexto em que essa tendência foi se delineando na organização do sistema de ensino brasileiro. A relação entre os modelos de racionalização típicos do sistema de produção capitalista serviu de orientação para o tecnicismo aplicado à educação.

No modelo tecnicista de educação, a exigência da produtividade do sistema de ensino, por intermédio da racionalização, propôs objetivos de ensino fragmentados. Há uma ênfase nos meios que passam a determinar os objetivos. Isto posto, há uma inversão no processo pedagógico, de modo que as técnicas determinam os fins. Em outros termos, ocorre uma mudança qualitativa na organização do trabalho pedagógico da escola, que passa a ter como base um ensino que busca resultado uniforme, com ênfase em métodos e técnicas de ensino e na valorização da utilização de manuais, livros didáticos, módulos de ensino e recursos audiovisuais. Em outros termos, o tecnicismo privilegiou as questões do que fazer educativo, partindo de uma dimensão marcadamente técnica. 
$\mathrm{Na}$ pedagogia tecnicista, as atividades de ensino englobam variados recursos (como os meios audiovisuais) e inúmeros exercícios caracterizados como estudo dirigido. Aos professores, cabem desenvolver essas atividades com base nos programas e nos manuais didáticos elaborados por outros, ou seja, os professores não participam das decisões curriculares. Os programas e os manuais didáticos destinados aos professores incluem modelos de provas, planos de aula e material de apoio para a preparação das atividades em sala de aula. Na tendência tecnicista, há ênfase na organização do processo pedagógico, do "máximo resultado com o mínimo de dispêndio" e, principalmente, na mecanização do processo (SAVIANI, 2007, p.379-380).

Sobre as mudanças nas relações de trabalho ocorridas nas últimas décadas, pode-se dizer que, em função da reestruturação do sistema de produção (taylorista/fordista/toyotista), também surgiram novas determinações para a escola e para a organização do trabalho pedagógico. Essas determinações apontam para mudanças nos processos produtivos, em que a racionalidade administrativa - característica do modelo empresarial - é transferida às instituições escolares.

Finalmente, também é importante pontuar a análise conceitual de Freitas (2011) válida para o contexto (neo)tecnicista mais recente, apresentado agora sob a forma de um processo de ensino e aprendizagem centrado nos resultados, onde se propõe a mesma racionalidade técnica dos anos setenta, para assim garantir a eficiência e a produtividade na educação. A meu ver, em função desse contexto, as políticas educacionais passam a enfatizar o critério da qualidade com base em um fundamento - a utilização intensiva das TIC como estratégia (muito mais sofisticada do que a tecnologia educacional dos anos setenta) de adequação da educação escolar à sociedade da informação.

\section{Referências}

ANTUNES, Ricardo. Os sentidos do trabalho. Ensaio sobre a afirmação e a negação do trabalho. São Paulo: Boitempo, 2009.

BRASIL. Lei $n^{\circ} 5.540$ de 28 de novembro de 1968. Fixa normas de organização e funcionamento do ensino superior e sua articulação com a escola média, e dá outras providências. Diário Oficial da União. Seção 1. Brasília: Casa Civil da Presidência da República, 1968.

BRASIL. Lei n. 5.692, de 20 de dezembro de 1971. Fixa as Diretrizes e Bases para o ensino de $1^{\circ}$ e $2^{\circ}$ graus, e dá outras providências. Diário Oficial da União. Brasília: Casa Civil da Presidência da República, 1971.

CHIAVENATO, Idalberto. Introdução à teoria geral da administração. São Paulo: McGraw-Hill, 2003.

DELORS, Jacques. Educação: um tesouro a descobrir. Relatório para a UNESCO da Comissão Internacional sobre Educação para o século XXI. Brasília: MEC/UNESCO, 1996.

DREIFUSS, R. A. 1964 - A conquista do Estado - Ação política, poder e golpe de classes. Petrópolis: Vozes, 1981.

FAIRCLOUGH, Norman. Discurso e mudança social. Brasília: Editora Universidade de Brasília, 2001. 
FREITAS, Luiz Carlos de. Responsabilização, meritocracia e privatização: conseguiremos escapar ao neotecnicismo? In: Seminário de Educação Brasileira, Centro de Estudos Educação e Sociedade, Campinas, fev. 2011.

KUENZER, Acácia Z., MACHADO, Lucília R. de Souza. A pedagogia tecnicista ln: MELO, G. (org.). Escola Nova; tecnicismo na educação compensatória. São Paulo: Loyola, 1986.

KUENZER, Acácia. Exclusão includente e inclusão excludente: a nova forma de dualidade estrutural que objetiva as novas relações entre educação e trabalho. In: SAVIANI, D.; SANFELICE, J.L.; LOMBARDI, J.C. (Org.). Capitalismo, trabalho e educação. 3. ed. Campinas: Autores Associados, 2005. p. 77-96.

LIBÂNEO, José Carlos. Saber, saber ser, saber fazer, o conteúdo do fazer pedagógico. Revista da ANDE, ano 1, 1982.

MANACORDA, Mario Alighiero. História da Educação: da antiguidade aos nossos dias. São Paulo: Cortez: Autores Associados, 1989.

PAIVA, Edil Vasconcellos, PAIXÃO, Lea Pinheiro. PABAEE (1956-1964): $a$ americanização do ensino elementar? Niterói: EdUFF, 2002.

SAVIANI, Dermeval. História das ideias pedagógicas no Brasil. São Paulo: Autores Associados, 2007.

SAVIANI, Dermeval. A pedagogia no Brasil: história e teoria. Campinas, SP: Autores Associados, 2008.

SAVIANI, Dermeval. A expansão do ensino superior no Brasil: mudanças e continuidades. Poíesis pedagógica, v.8, N.2 ago. /dez.2010; pp.4-17.

SCHULTZ, Theodore W. Investment in Human Capital. The American Economic Review, $\mathrm{p}$ $1-17,1961$.

SILVA, João Carlos da. Utopia Positivista e instrução pública no Brasil. Revista HISTEDBR On-line, Campinas, n.16, p. 10 - 16, dez. 2004.

\footnotetext{
${ }^{1}$ ProPEd / UERJ. Professora do Ensino Superior FAETEC/ISERJ. E-mail: av.mafra@ hotmail.com

${ }^{2}$ As principais obras de Frederick Winslow Taylor são Shop management (1903), que trata das técnicas de racionalização do trabalho do operário, por meio do estudo de tempos e movimentos (Motion-time Study), e Principles of scientific management (1911), ambas com base ideológica de apologia ao corporativismo. O livro Principles of scientific management (1911) relata as experiências de trabalho de Frederick Winslow Taylor, desde o início da sua carreira na Enterprise Hydraulic Works, onde ingressou como aprendiz e na Midvale Steel Company, onde iniciou como operário especializado até alcançar o posto de engenheiro chefe de oficinas (TAYLOR, 1911). Taylor foi também consultor de várias empresas e frequentemente proferia conferências em estabelecimentos industriais discursando sobre métodos científicos cartesianos na administração das empresas (idem).

${ }^{3}$ C.f. http://www.ideafinder.com/history/inventors/ford.htm Acesso em 14 mar 2017.
} 
${ }^{4}$ As formulações, a partir desse ponto, têm como referência a síntese de Ricardo Antunes (2009) sobre os modelos de produção - taylorismo/ fordismo.

${ }^{5}$ Op. Cit.

6 João Belchior Marques Goulart (1919 -1976), conhecido popularmente como "Jango", foi um advogado e político brasileiro, $24^{\circ}$ presidente do país, de 1961 a 1964. Antes disso, também foi vice-presidente, de 1956 a 1961, tendo sido eleito com mais votos que o próprio presidente, Juscelino Kubitschek. Formou-se em Direito na Universidade Federal do Rio Grande do Sul em 1939. Foi deposto pelo Golpe Militar de 1964, liderado pelo alto escalão do Exército. Fonte: CASTELO BRANCO, C. Introdução à Revolução de 1964 - a queda de João Goulart. RJ: Artenova, 1975.

${ }^{7}$ Op. Cit.

Recebido: Abril/2016.

Aprovado: Março/2017. 